\title{
Fractionation of heavy metals in surface sediments of Taihu Lake, East China
}

\author{
H. Wang ${ }^{1}$, C.X. Wang ${ }^{1,3}$, Z.J. Wang ${ }^{1} \&$ Z.H. Cao ${ }^{2}$ \\ ${ }^{1}$ State Key Laboratory of Environmental Aquatic Chemistry, Research Center for Eco-Environmental \\ Sciences, Chinese Academy of Sciences, Beijing 100085, PR China \\ ${ }^{2}$ Institute of Soil Sciences, Chinese Academy of Sciences, Nanjing 210000, PR China \\ ${ }^{3}$ Author for correspondence (tel.: +86-10-62849107; fax: +86-10-62923543; e-mail: Chunxia@mail.rcees. \\ ac.cn)
}

Received 17 February 2003 Accepted 18 August 2003

Key words: BCR, heavy metals, sediment, Taihu Lake, total organic carbon

\begin{abstract}
The BCR (European Communities Bureau of Reference) three-step sequential extraction procedure was applied to fractionate heavy metals in the sediment of Taihu Lake. For the determination of total metal concentration of the sediments, sample digestion was achieved by using $\mathrm{HF} / \mathrm{H}_{2} \mathrm{O}_{2} / \mathrm{HNO}_{3}(2 / 1 / 1)$ acid mixture in a microwave-irradiated closed vessel system. The concentrations of $\mathrm{Cd}, \mathrm{Ni}, \mathrm{Cr}, \mathrm{Zn}, \mathrm{Cu}$ and $\mathrm{Pb}$ in various extracts solutions were analyzed by Inductively Coupled Plasma Atomic Emission Spectrometry (ICP-AES). The results obtained from the BCR three-step sequential extraction indicated relatively high mobility of $\mathrm{Zn}, \mathrm{Cu}, \mathrm{Pb}$ and $\mathrm{Ni}$ in the sediments while $\mathrm{Cd}$ and $\mathrm{Cr}$ were poorly mobile. Enrichment of heavy metals was found in the sediments collected in the northern parts of Taihu Lake. In the sediments collected in the southern and western sides of the Lake, heavy metal concentrations were relatively low. The relationship between total organic carbon (TOC) and heavy metals concentrations in the sediments is discussed.
\end{abstract}

\section{Introduction}

Sediment constitutes the most important sink of metals and other pollutants, it can act as a nonpoint source and have the potential to release the sediment-bound metals and other pollutants to overlying waters, and in turn adversely affects aquatic organisms.

As the third largest freshwater lake of China with water surface area of $2334 \mathrm{~km}^{2}$, the Taihu Lake region holds $0.4 \%$ of the nation's total area $1,2.9 \%$ of the nation's population, and more than $14 \%$ of the gross domestic production (GDP). The Lake is an important source of drinking water for the residents living nearby, and also for freshwater fisheries. The lake has been contaminated by industrial and household effluent combined with agricultural run-off, and for decades, the water quality of the lake has been deteriorating (Jin \& Ye 1999).
Total metal analysis may provide information concerning possible enrichment of heavy metals in sediment, but it is often assumed that heavy metals with different forms have different bioavailability and toxicity to plants and animals. When the possible biological effects of trace metals in sediments need to be evaluated, additional studies are required. However, very little information is available on the heavy metal fractionation status in the sediment of Taihu Lake.

The objective of this study was to determine the concentration, distribution and fractionation of heavy metals in the sediment of Taihu Lake.

Microwave-assisted acid solubilization has been proved to be the most suitable method for the digestion of complex matrices such as sediments and soils (USEPA 1995; Kingston 1998). This method shortens the digestion time, reduces the risk of external contamination and uses smaller 
quantities of acids, thereby improving detection limits and the overall accuracy of analytical method.

Among various sequential extraction procedures (Matzner \& Prenzel 1992; Gupta et al. 1996; McGrath 1996) in fractionation of heavy metals in soil, those described by Tessier et al. (1979) and Salomons and Forstner (1984) have received wide application. In the late 1980s, measurements and testing program (formerly BCR) organized a project for studying mobility and availability of metals in sediments which reached a compromise between analysis time and the amount of information obtained.

In the present study, the sequential extraction procedure designed by the $\mathrm{BCR}$ was applied to determine the solid-phase distribution of trace metals in sediments of Taihu Lake. The microwave digestion technique was used to digest the sediment samples for the estimation of total metal contents. The leachable parts from sequential extraction were determined by ICP-AES analysis. The relationship between trace metal partitioning and TOC content in sediment was also investigated.

\section{Materials and methods}

\subsection{Sampling}

Twelve sediment samples were collected with a Van Veen grab in Taihu Lake in November 2000 as shown in Figure 1. At each sampling site, $1 \mathrm{~kg}$ of sediment was collected and stored in polyethylene bags.

\subsection{Sample preparation}

Sediment samples were freeze-dried by a Yamato freeze dryer, homogenized and sieved $(2 \mathrm{~mm})$. $\mathrm{pH}$ of the sediment samples was determined according to Folson et al. (1981).

\subsection{Total metal concentration analysis}

0.1 g sediment sample was put in a Teflon PFA microwave vessel, adding $4 \mathrm{~mL} \mathrm{HF} / \mathrm{H}_{2} \mathrm{O}_{2} / \mathrm{HNO}_{3}$ $(2 / 1 / 1)$ acid mixture, and left in contact with the acid solution for $4 \mathrm{~h}$. The vessel was then sealed and heated in the microwave oven. After cooling, the clear solution obtained was quantitatively transferred into a $50 \mathrm{~mL}$ flask and brought to volume with deionized water and analyzed by ICPAES.

\subsection{BCR three-step sequential extraction procedure}

The sequential extraction protocol proposed by the BCR (Ure et al. 1992) was applied to fractionate heavy metals of $\mathrm{Cd}, \mathrm{Ni}, \mathrm{Cr}, \mathrm{Zn}, \mathrm{Cu}$ and $\mathrm{Pb}$. This protocol produced three independent fractions. They are B1: acetic acid extractable fraction or exchangeable fraction, B2: acidic hydroxylamine extractable metals or acid reducible fraction, and B3: acidic hydrogen peroxide extractable metals or organic fraction. The residual metals B4 were also determined by the same method as total

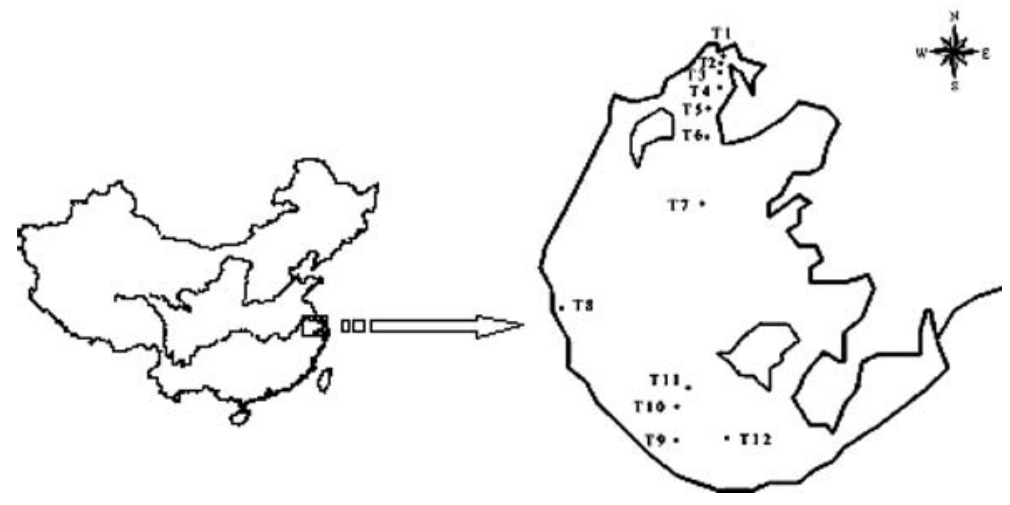

Fig. 1. Map of Taihu Lake showing sampling locations. 
metal concentration analysis. The insoluble residue (B4) represents the portion of metals bound to silicate lattice or crystalline iron and manganese oxides.

For the BCR extraction, the first step was to shake the sediment sample with $40 \mathrm{~mL}$ $0.11 \mathrm{~mol} \mathrm{~L}^{-1}$ acetic acid (HOAc; $\mathrm{pH} 2.9$ ) for $16 \mathrm{~h}$, followed by centrifugation and collection of the supernatant. The solid was rinsed with deionised water and centrifuged again. The residue was then shaken with $40 \mathrm{~mL} 0.1 \mathrm{~mol} \mathrm{~L}^{-1}$ hydroxylamine hydrochloride $\left(\mathrm{NH}_{2} \mathrm{OH}-\mathrm{HCl}\right.$; $\mathrm{pH}$ 2) for $16 \mathrm{~h}$, before repeating the centrifugation and rinse as in the first step. The third step involved digesting with $10 \mathrm{ml} \mathrm{30 \%} \mathrm{(w/v)} \mathrm{hydrogen} \mathrm{peroxide} \mathrm{for} 1 \mathrm{~h}$ at room temperature, adding a further $10 \mathrm{~mL} \mathrm{H}_{2} \mathrm{O}_{2}$ and digesting for $1 \mathrm{~h}$ at $85^{\circ} \mathrm{C}$. The solution was then reduced to a few $\mathrm{mL}$ before adding $50 \mathrm{~mL}$ $1 \mathrm{~mol} \mathrm{~L}^{-1}$ ammonium acetate $\left(\mathrm{NH}_{4} \mathrm{Ac} ; \mathrm{pH} 2\right)$ to the residue and shaking for $16 \mathrm{~h}$. The supernatant was collected after centrifugation.

\subsection{Technical details}

TOC of sediments were determined by Tocmeter (Tekmar-Dohrmann Apollo 9000, USA). Microwave oven (CEM MDS 2000, USA) was used to digest the samples. The operating frequency of the oven was $2450 \mathrm{MHz}$, maximum power was about $600 \mathrm{~W}$. Cd,
$\mathrm{Ni}, \mathrm{Cr}, \mathrm{Zn}, \mathrm{Cu}$ and $\mathrm{Pb}$ concentrations were determined by ICP-AES (Jarrell-Ash Icap 9000, USA).

Stock standard solutions of $\mathrm{Cd}, \mathrm{Ni}, \mathrm{Cr}, \mathrm{Zn}, \mathrm{Cu}$ and $\mathrm{Pb}\left(1000 \pm 2 \mathrm{mg} \mathrm{L}^{-1}\right.$ in $\left.5 \% \mathrm{HNO}_{3}\right)$ were obtained from National Standard Materials Center of China. All other chemicals were of analytical grade. Glassware used was cleaned by soaking in a 1:1 (v/v) nitric acid solution overnight and then rinsed with deionized water.

\section{Results and discussions}

\subsection{Total concentrations of heavy metals in sediment}

Total concentrations of $\mathrm{Cd}, \mathrm{Ni}, \mathrm{Cr}, \mathrm{Zn}, \mathrm{Cu}$, and $\mathrm{Pb}$ determined in the sediments of Taihu Lake are presented in Table 1. Sampling sites T6 and T12 can be considered as unpolluted with no special inputs, the increase in agricultural and industrial activities combined with human wastes, were connected with metal levels found in the north of Taihu Lake. This increase was particularly significant for $\mathrm{Cu}, \mathrm{Zn}$ and $\mathrm{Ni}$ in the most urban and industrial stations (T1-T2). The sequence of heavy metal concentrations was north bank $>$ south bank $>$ west bank $>$ center of the Lake. This result demonstrate that the effluent from a larger city (Wuxi) contained larger amounts of heavy

Table 1. Total metal concentrations in surface sediments of Taihu Lake.

\begin{tabular}{|c|c|c|c|c|c|c|c|c|c|}
\hline \multirow{2}{*}{$\begin{array}{l}\text { Sampling } \\
\text { sites }\end{array}$} & \multirow[t]{2}{*}{ Latitude } & \multirow[t]{2}{*}{ Longitude } & \multirow[t]{2}{*}{$\mathrm{pH}$} & \multicolumn{6}{|c|}{ Concentration $\left(\mathrm{mg} \mathrm{kg}^{-1}\right)$} \\
\hline & & & & $\mathrm{Cr}$ & $\mathrm{Cu}$ & $\mathrm{Zn}$ & $\mathrm{Cd}$ & $\mathrm{Ni}$ & $\mathrm{Pb}$ \\
\hline $\mathrm{T} 1$ & $31^{\circ} 32^{\prime} 14^{\prime \prime} \mathrm{N}$ & $120^{\circ} 13^{\prime} 17^{\prime \prime} \mathrm{E}$ & 7.17 & 162.1 & 102.2 & 370.3 & 6.2 & 121.4 & 388.3 \\
\hline $\mathrm{T} 2$ & $31^{\circ} 32^{\prime} 00^{\prime \prime} \mathrm{N}$ & $120^{\circ} 12^{\prime} 04^{\prime \prime} \mathrm{E}$ & 7.40 & 146.2 & 68.2 & 209.4 & 8.9 & 89.6 & 495.4 \\
\hline $\mathrm{T} 3$ & $31^{\circ} 30^{\prime} 09^{\prime \prime} \mathrm{N}$ & $120^{\circ} 12^{\prime} 02^{\prime \prime} \mathrm{E}$ & 7.25 & 85.6 & 33.4 & 141.9 & 4.9 & 41.9 & 286.6 \\
\hline T4 & $31^{\circ} 28^{\prime} 43^{\prime \prime} \mathrm{N}$ & $120^{\circ} 11^{\prime} 48^{\prime \prime} \mathrm{E}$ & 7.43 & 141.7 & 52.1 & 206.0 & 6.8 & 65.3 & 443.5 \\
\hline T5 & $31^{\circ} 26^{\prime} 45^{\prime \prime} \mathrm{N}$ & $120^{\circ} 11^{\prime} 24^{\prime \prime} \mathrm{E}$ & 7.41 & 136.4 & 42.0 & 135.1 & 8.4 & 63.3 & 482.6 \\
\hline T6 & $31^{\circ} 24^{\prime} 59^{\prime \prime} \mathrm{N}$ & $120^{\circ} 11^{\prime} 16^{\prime \prime} \mathrm{E}$ & 7.40 & 95.7 & 31.2 & 78.3 & 3.9 & 40.3 & 258.9 \\
\hline $\mathrm{T} 7$ & $31^{\circ} 20^{\prime} 15^{\prime \prime} \mathrm{N}$ & $120^{\circ} 10^{\prime} 53^{\prime \prime} \mathrm{E}$ & 7.45 & 91.0 & 28.6 & 113.3 & 4.8 & 35.4 & 269.2 \\
\hline $\mathrm{T} 8$ & $31^{\circ} 11^{\prime} 29^{\prime \prime} \mathrm{N}$ & $119^{\circ} 55^{\prime} 32^{\prime \prime} \mathrm{E}$ & 7.23 & 106.1 & 34.5 & 156.5 & 7.3 & 46.5 & 408.1 \\
\hline T9 & $30^{\circ} 59^{\prime} 15^{\prime \prime} \mathrm{N}$ & $120^{\circ} 07^{\prime} 51^{\prime \prime} \mathrm{E}$ & 7.22 & 86.2 & 9.7 & 75.9 & 4.6 & 36.8 & 329.2 \\
\hline T10 & $31^{\circ} 01^{\prime} 43^{\prime \prime} \mathrm{N}$ & $120^{\circ} 08^{\prime} 10^{\prime \prime} \mathrm{E}$ & 7.16 & 102.1 & 34.3 & 137.2 & 5.7 & 42.1 & 384.3 \\
\hline T11 & $31^{\circ} 03^{\prime} 36^{\prime \prime} \mathrm{N}$ & $120^{\circ} 08^{\prime} 51^{\prime \prime} \mathrm{E}$ & 7.23 & 126.2 & 47.5 & 150.4 & 6.3 & 46.3 & 404.2 \\
\hline T12 & $30^{\circ} 58^{\prime} 46^{\prime \prime} \mathrm{N}$ & $120^{\circ} 13^{\prime} 23^{\prime \prime} \mathrm{E}$ & 7.16 & 84.4 & 31.9 & 71.6 & 4.8 & 33.5 & 336.5 \\
\hline Mean & & & 7.29 & 113.6 & 44.6 & 153.8 & 6.05 & 55.2 & 373.9 \\
\hline
\end{tabular}


metals than a smaller city (Huzhou), and that the center of the Lake was relatively clean.

\subsection{Fractionation of heavy metals in sediments}

Concentrations of heavy metals in the sediments of Taihu Lake in the four fractions are summarised in Figure 2, and compared to the total metal concentrations. The mass balance agreed within $\pm 7 \%$
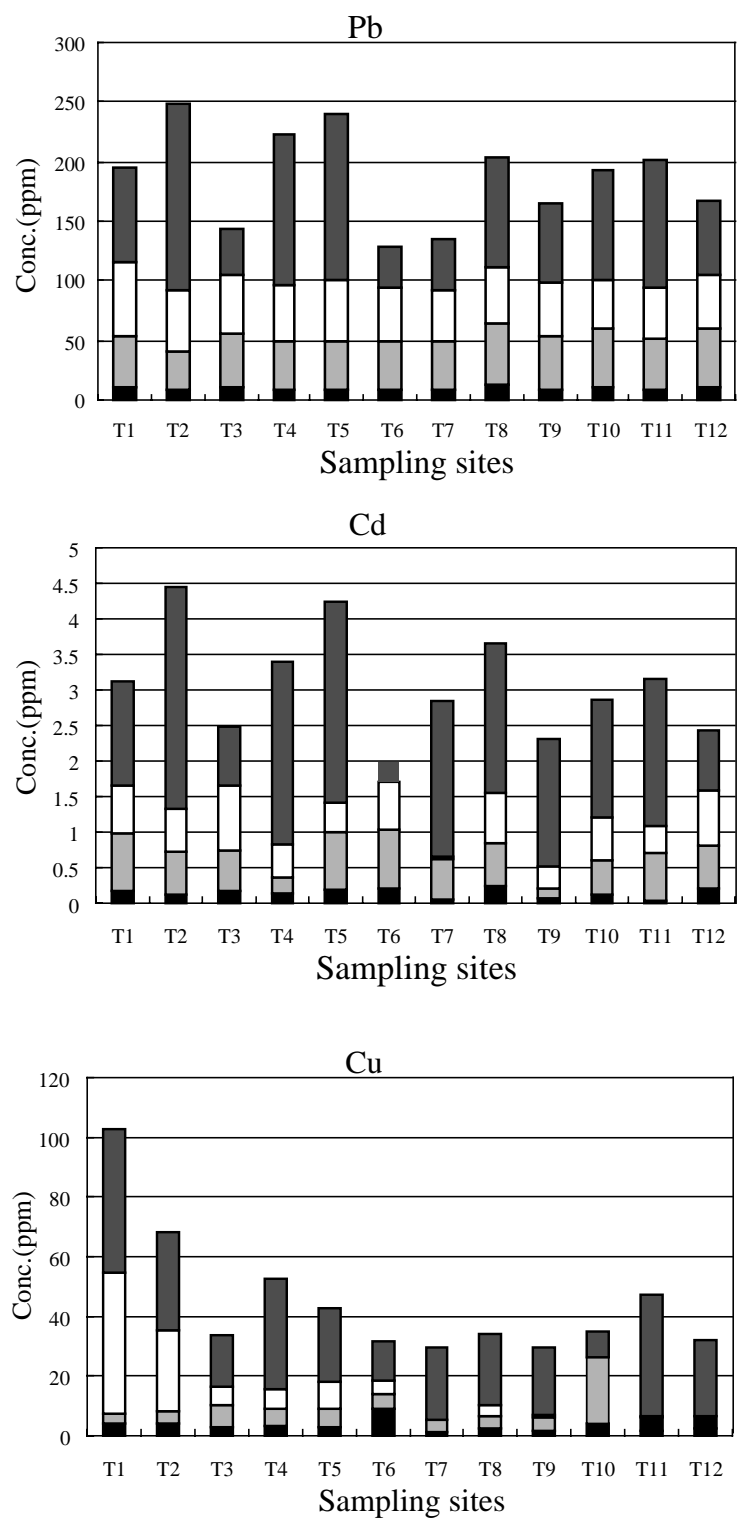

B1 $\square$ B2 $\square$ B3 $\square$ B4 for $\mathrm{Cd}, \mathrm{Cr}, \mathrm{Cu}$, and within $\pm 9 \%$ for $\mathrm{Ni}, \mathrm{Pb}$ and $\mathrm{Zn}$. The extractable fractions of heavy metals in $0.11 \mathrm{~mol} \mathrm{~L}^{-1}$ acetic acid were very low for $\mathrm{Cr}$ (1.05\%), moderate for $\mathrm{Pb}, \mathrm{Cd}$ and $\mathrm{Cu}(4.6-10.5 \%)$ and relatively high for $\mathrm{Ni}$ and $\mathrm{Zn}(13.7-13.9 \%)$. More than $25 \%$ of the total $\mathrm{Zn}$ and $\mathrm{Ni}$ were released in the B2 fraction, the portions in this fraction for other heavy metals were $3.03 \%$ for $\mathrm{Cr}$, $21.5 \%$ for $\mathrm{Pb}, 14 \%$ for $\mathrm{Cu}$ and $18.75 \%$ for $\mathrm{Cd}$. Ni,
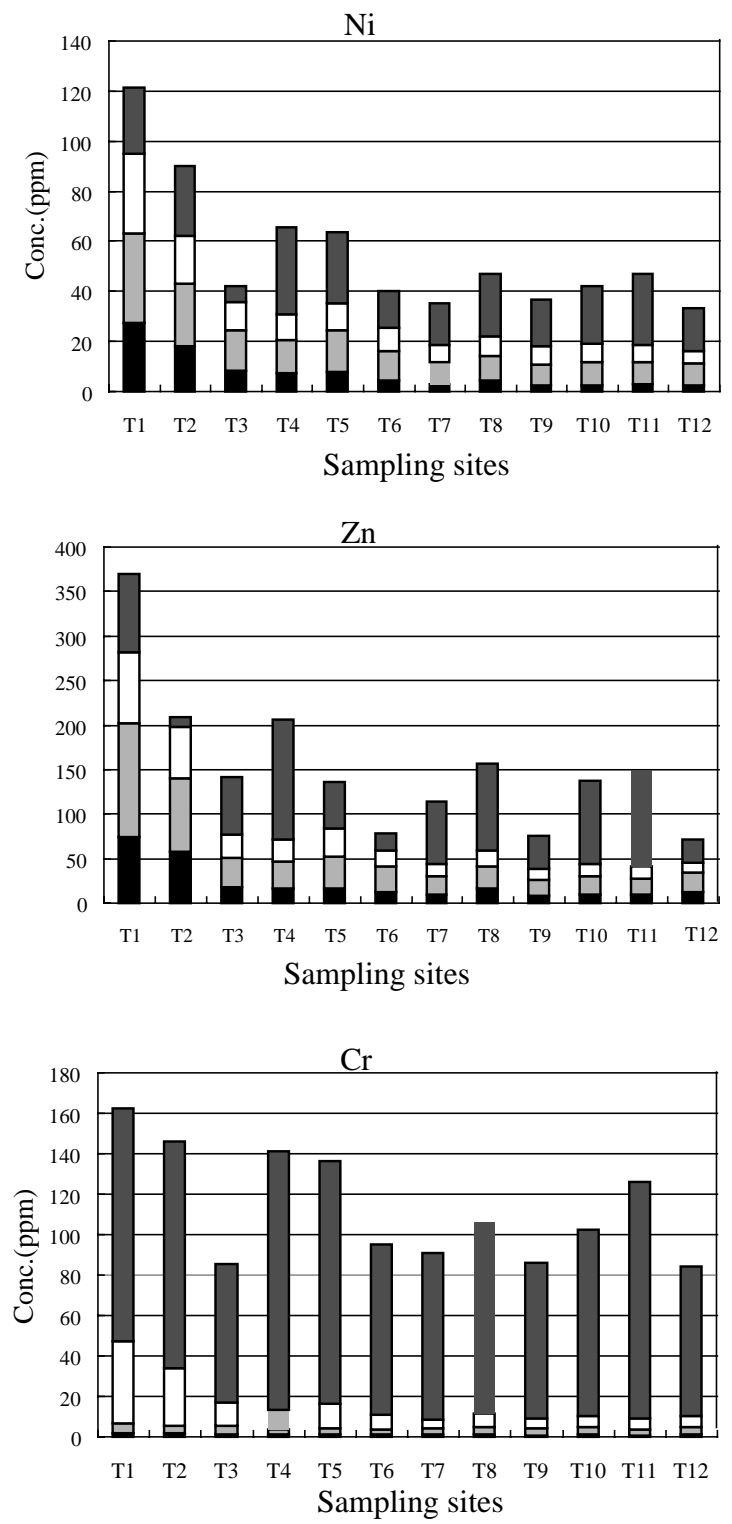

Fig. 2. Distribution of heavy metal speciation in the sediments of Taihu Lake. 
$\mathrm{Cu}, \mathrm{Cd}, \mathrm{Pb}$ and $\mathrm{Zn}$ released in the $\mathrm{B} 3$ fraction varied from 17.47 to $26.01 \%$, while $\mathrm{Cr}$ was smaller $(10.4 \%)$. In the B4 fraction, $\mathrm{Cr}$ took up the highest percentage of $85.4 \%, \mathrm{Cu}$ and $\mathrm{Cd}$ the second (75.10\%), $\mathrm{Zn}, \mathrm{Pb}$ and $\mathrm{Ni}$ took up the lowest percentage of $41.72-53.44 \%$. Copper can easily complex with organic matter because of the high formation constant of organic- $\mathrm{Cu}$ compounds (Stumm \& Morgan 1981). In this study, Cu was primarily present in the residual fraction (B4) or associated with the organic fraction (B3), this result agrees with those found in the literature (Tessier et al. 1979). In agreement with several other papers (Tuin \& Tels 1990) is the high variability that was found for the chemical forms of $\mathrm{Zn}$ associated with the different sediment fractions, The increase in the levels of the most bioavailable forms (B1\&B2) of $\mathrm{Ni}$ and $\mathrm{Zn}$ in $\mathrm{T} 1$ and $\mathrm{T} 2$ was associated with industrial or, specifically, urban activities. Similar variations in the percentages, corresponding to the different fractions extracted from sediments, being dependent upon the economic activity of the area has been previously described in the literature. $\mathrm{Cd}$ had been a cause of concern due to its hazardous environmental implications, however the low content of Cd (below 5\%) as B1 form indicates that $\mathrm{Cd}$ may not easily be taken up by living organisms.

It is assumed that the total organic carbon (TOC) can serve as a matrix on particle surfaces for complexing metals. Seidemann (1991) found a strong correlation between the percentage of TOC and metal pollution in sediment of an urban estuary. However, the relationship between the concentrations of heavy metals in different fractions and TOC is not well documented. In this study, the correlation matrix analysis between the TOC of sediment and the concentrations of heavy metals in total, and in B1, B2 and B3 fractions were carried out and tabulated in Tables 2 and 3, respectively. (the concentration data are not shown). It can be seen that in the first matrix, $\mathrm{Ni}$ and $\mathrm{Cu}$ have the highest correlation with TOC $(r=0.88-0.93)$. The coefficient of TOC and metal concentrations for $\mathrm{Zn}$ and $\mathrm{Cr}$ are smaller $(r=0.73-0.79) . \mathrm{Cd}$ and $\mathrm{Pb}$ concentrations have no significant correlation with TOC. The first matrix also shows that $\mathrm{Cr}$ has a high coefficient with all the other five heavy metals $(r>0.73) . \mathrm{Cu}$ has a high coefficient with $\mathrm{Zn}$ and $\mathrm{Ni}(r>0.95), \mathrm{Zn}$ was significantly correlated only with $\mathrm{Ni}(r=0.93)$, while Cd was significantly correlated only with $\mathrm{Pb}$. The significant correlations may be related to the similar source and distribution pattern of these metals.

In the fractions of extractable forms of heavy metals in $0.11 \mathrm{~mol} \mathrm{~L}^{-1}$ acetic acid (water-soluble, exchangeable and carbonate-bound), a significant correlation $(r>0.90)$ has been identified among $\mathrm{Cr}, \mathrm{Zn}$, and $\mathrm{Ni}$ with TOC. There was also a significant correlation between $\mathrm{Cr}-\mathrm{Zn}(0.957), \mathrm{Cr}-\mathrm{Ni}$ (0.973) and $\mathrm{Zn}-\mathrm{Ni}(0.982)$. In the $\mathrm{B} 2$ fraction, extractable in hydroxylamine hydrochloride (heavy metals bound to iron and manganese oxides and hydroxides), a significant correlation $(r>0.90)$ has been identified between $\mathrm{Zn}$, Ni with TOC. There was also a significant correlation between $\mathrm{Zn}$ and $\mathrm{Ni}$ (0.983). In the third moderately soluble fraction (heavy metals bound to organic matter and sulfides), a significant correlation $(r>0.90)$ has been observed among $\mathrm{Cr}, \mathrm{Cu}, \mathrm{Zn}$, $\mathrm{Ni}$ and $\mathrm{Pb}$ with TOC, there were also significant correlations between $\mathrm{Cr}-\mathrm{Cu}$ (0.996), $\mathrm{Cr}-\mathrm{Zn}$ (0.995), $\mathrm{Cr}-\mathrm{Pb}$ (0.938), $\mathrm{Cu}-\mathrm{Zn}$ (0.992), $\mathrm{Cu}-\mathrm{Ni}$ (0.992), $\mathrm{Cu}-\mathrm{Pb}(0.941)$ and $\mathrm{Zn}-\mathrm{Ni}(0.980)$. It is clear that in the third fraction more metals had significant correlations with TOC than that in the first and second fractions.

Table 2. Correlation matrix of TOC and total metal concentration.

\begin{tabular}{lllllll}
\hline Total & TOC & $\mathrm{Cr}$ & $\mathrm{Cu}$ & $\mathrm{Zn}$ & $\mathrm{Cd}$ & $\mathrm{Ni}$ \\
\hline $\mathrm{Cr}$ & 0.7342 & & & & & \\
$\mathrm{Cu}$ & 0.8820 & 0.8726 & & & & \\
$\mathrm{Zn}$ & 0.7946 & 0.8392 & 0.9457 & & & \\
$\mathrm{Cd}$ & 0.4523 & 0.7296 & 0.4456 & 0.4473 & & \\
$\mathrm{Ni}$ & 0.9263 & 0.8994 & 0.9760 & 0.9327 & 0.5569 & \\
$\mathrm{~Pb}$ & 0.4029 & 0.7633 & 0.4747 & 0.4464 & 0.9443 & 0.5512 \\
\hline
\end{tabular}


Table 3. Correlation matrix of TOC and metal concentrations (B1, B2 and B3 fractions).

\begin{tabular}{lclllll}
\hline & TOC & $\mathrm{Cr}$ & $\mathrm{Cu}$ & $\mathrm{Zn}$ & $\mathrm{Cd}$ & $\mathrm{Ni}$ \\
\hline $\mathrm{B1}$ & & & & & & \\
$\mathrm{Cr}$ & 0.9371 & & & & & \\
$\mathrm{Cu}$ & 0.2197 & 0.1755 & & & & \\
$\mathrm{Zn}$ & 0.9591 & 0.9573 & 0.2061 & & & \\
$\mathrm{Cd}$ & 0.1450 & 0.3043 & 0.4469 & 0.1306 & & \\
$\mathrm{Ni}$ & 0.9612 & 0.9732 & 0.2130 & 0.9822 & 0.1587 & \\
$\mathrm{~Pb}$ & -0.092 & 0.1889 & -0.0412 & 0.0627 & 0.5859 & 0.0207 \\
$\mathrm{~B} 2$ & & & & & & \\
$\mathrm{Cr}$ & 0.3364 & & & & & \\
$\mathrm{Cu}$ & -0.3187 & 0.2341 & & & & \\
$\mathrm{Zn}$ & 0.9519 & 0.4844 & -0.2336 & & & \\
$\mathrm{Cd}$ & 0.2570 & 0.1517 & -0.1752 & 0.3801 & & \\
$\mathrm{Ni}$ & 0.9452 & 0.4635 & -0.2187 & 0.9827 & 0.4013 & \\
$\mathrm{~Pb}$ & -0.5863 & 0.3869 & 0.3043 & -0.4221 & -0.1162 & \\
$\mathrm{B3}$ & & & & & & \\
$\mathrm{Cr}$ & 0.9615 & & & & & \\
$\mathrm{Cu}$ & 0.9498 & 0.9958 & & & & \\
$\mathrm{Zn}$ & 0.9607 & 0.9950 & 0.9918 & & & \\
$\mathrm{Cd}$ & 0.1999 & 0.2728 & 0.2472 & 0.2472 & & \\
$\mathrm{Ni}$ & 0.9265 & 0.9839 & 0.9919 & 0.9800 & 0.2407 & \\
$\mathrm{~Pb}$ & 0.9031 & 0.9379 & 0.9407 & 0.9527 & 0.3410 & 0.9357 \\
\hline
\end{tabular}

\section{Conclusions}

1. The total concentrations of heavy metals in the sediments collected in the northern parts of the Taihu Lake were higher than that concentrations in the southern and western sides of the Lake.

2. The portions of heavy metals, based on BCR three-step sequential extraction procedure, indicates relatively high mobility of $\mathrm{Zn}, \mathrm{Cu}, \mathrm{Pb}$ and $\mathrm{Ni}$ in the sediments: $\mathrm{Cr}$ and $\mathrm{Cd}$ were mainly in the B4 fractions and hence poorly mobile.

3. The relationship between the concentrations of heavy metals to each other suggest that $\mathrm{Zn}, \mathrm{Cu}$ and $\mathrm{Ni}$ probably came from the same kind of pollution source.

4. In the B3 fraction more metals had significant correlations with TOC than those of the B1 and B2 fractions, which indicates that the identification of the third fraction as the partition of heavy metals bound to organic matter and sulphides is reasonable.

\section{Acknowledgements}

This work was supported by National Natural Science Foundation of China (20037010) and National Basic Key Research Project (G19990118-06).

\section{References cited}

Folson BL, Lee CR, Bates DJ. 1981 Influence of disposal environment on availability and plant uptake of heavy metals in dredge material, Technical Report EL-81-12, US Army, Washington, DC, 20314, p. 151.

Gupta SK, Vollmer MK, Krebs R. 1996 The importance of mobile, mobilisable and psedo total heavy metal fractions in soil for three-level risk assessment and risk management. Sci Total Environ 178, 11-20.

Jin XC, Ye C. 1999 Comprehensive treatment plan for keypolluted regions of Lake Taihu. Res Environ Sci 5, 1-5.

Kingston HM. 1998 Standardization of sample preparation for trace element determination through microwave-enhanced chemistry. Atomic Spectrosc 2, 27-30.

Matzer E, Prenzel J. 1992 Acid deposition in the German soiling area: effects on soil solution chemistry and AL mobilisation. Water Air Soil Pollut 61, 221-234. 
McGrath D. 1996 Application of single and sequential extraction procedure to polluted and unpolluted soils. Sci Total Environ 178, 37-44.

Ramos L, Hernández LM, González MJ. 1994 Sequential fractionation of copper, lead, cadmium and zinc in soils from or near Doñana National Park. J Environ Qual 23, 50-57.

Salomons W, Forstner U. 1984 Metals in the Hydrocycle. Berlin: Springer.

Seidemann DE. 1991 Metal pollution in sediment of Jamaica Bay, New York, USA - an Urban estuary. Environ Manage 15, 73-81.

Stumm W, Morgan JJ. 1981 Aquatic Chemistry: An Introduction Emphasizing Chemical Equilibria in Natural Water, 2nd ed. New York: John Willy \& Sons.
SW-846 EPA Method 3052. 1995 Microwave assisted acid digestion of siliceous and organically based matrices. In test methods for evaluating solid waste, 3rd update. Washington, DC: U.S.EPA.

Tessier A, Campbell PGC, Bisson M. 1979 Sequential extraction procedure for the speciation of trace metals. Anal Chem 51, 844-851.

Tuin BJW, Tels M. 1990 Distribution of six heavy-metals in contaminated clay soils before and after extractive cleaning. Environ Pollut 14, 47-61.

Ure AM, Quevauviller Ph, Muntau H, Griepink B. 1992 EUR Report No. 14763. CEC. Brussels. 